\title{
Tumor-initiating cells contribute to radiation resistance in primary human renal clear cell carcinomas by activating the DNA damage checkpoint response
}

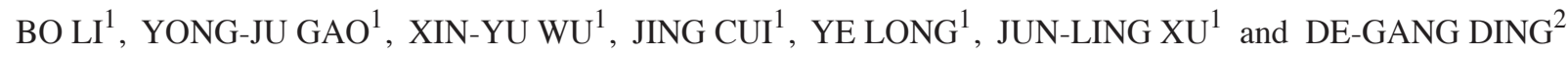 \\ Departments of ${ }^{1}$ Nuclear Medicine and ${ }^{2}$ Urology Surgery, Henan Provincial People's Hospital and \\ The People's Hospital of Zhengzhou University, Zhengzhou, Henan 450003, P.R. China
}

Received January 13, 2016; Accepted October 27, 2016

DOI: $10.3892 / 01.2017 .6504$

\begin{abstract}
The use of radiotherapy in patients with clear cell renal carcinoma (ccRCC) is predominantly limited to palliation of metastases or control of local growth, because ccRCC cells readily develop radioresistance. The mechanisms underlying ccRCC resistance remain elusive. The present study demonstrated that ccRCC cells that survive fractionated radiation treatment display tumor-initiating cell (TIC) characteristics, such as high self-renewal and tumorigenic capacities, and overexpress stemness genes. ccRCC cells that survived fractionated radiation exhibited increased activation of the DNA damage checkpoint response and G2/M phase arrest compared with sham-irradiated cells. The results of the present study suggest that ionizing radiation destroys the bulk of tumor cells within ccRCC, but spares TICs; this subpopulation confers ccRCC radioresistance and may cause tumor recurrence or relapse following radiotherapy. Furthermore, these findings indicate that the DNA damage checkpoint response may serve as a potential therapeutic target for overcoming resistance of TICs in patients with ccRCC.
\end{abstract}

\section{Introduction}

Renal cell carcinoma (RCC) is a common form of urological malignancy. It accounts for $2.6 \%$ of adult malignancies globally, and its incidence has steadily risen over the past decade (1-3). According to the Heidelberg classification system, the histological subtypes of RCC include chromophobe, clear cell, papillary, and unclassified carcinomas (2).

Correspondence to: Professor De-Gang Ding, Department of Urology Surgery, Henan Provincial People's Hospital and The People's Hospital of Zhengzhou University, 7 Weiwu Road, Zhengzhou, Henan 450003, P.R. China

E-mail: 13503848199@163.com

Key words: renal clear cell carcinoma, tumor initiating cells, radiation resistance, DNA damage checkpoint, ionizing radiation
The most common subtype of RCC is clear cell RCC (ccRCC), accounting for $\sim 82 \%$ of RCCs (3).

Patients with RCC display a high metastatic index, with one third of patients presenting with metastatic disease at initial diagnosis or following nephrectomy (4). Therapeutic approaches for RCC are multifaceted and include surgery, immunomodulatory therapy, radiotherapy and targeted therapy (1,5). Despite the widespread use of multimodal treatments, patients with RCC generally have poor prognoses (4). $\mathrm{RCC}$ is considered to be a radioresistant tumor, and the molecular mechanisms underlying this radiation resistance remain largely unknown. This resistance to current therapies severely limits the clinical management of RCC in patients. Thus, radiotherapy is used mostly for palliation of metastases or local tumor growth (6).

Recent research has identified a rare subpopulation of cancer stem cells, otherwise known as tumor-initiating cells (TICs), in malignant tumors (including RCC) that may confer resistance to radiotherapy $(7,8)$. A number of studies have isolated pools of TICs from RCC cell lines and tumor specimens (9-14). RCC TICs appear to be responsible for malignancy progression, relapse and metastasis (8-13). Zhong et al (12) have demonstrated that stem cell-like mammospheres from the RCC cell line SK-RC-42 exhibited greater resistance to irradiation than monolayers. Furthermore, several genetic and cellular adaptations within TICs may confer resistance to radiation. These adaptations include efficient DNA repair, free radical scavenging, upregulated cell cycle control, relative quiescence cell cycle kinetics and specific interactions with the stromal microenvironment (15).

TIC-mediated radiation resistance has been reported in various tumors; however, the correlation between radiation resistance and TICs in RCC remains elusive. The present study aims to investigate the role of TICs in radiation resistance and describe the molecular characteristics of RCC TICs.

\section{Materials and methods}

Isolation of primary RCC cells from human ccRCC tumors. Tumor specimens were obtained from patients at the Henan Provincial People's Hospital and the People's Hospital of Zhengzhou University (Zhengzhou, China). All patients gave 
informed consent for their tumor samples to be used. The present study was approved by the Internal Review and the Ethics Boards of Henan Provincial People's Hospital and the People's Hospital of Zhengzhou University. Tumor samples were isolated from a 47-year-old male patient with ccRCC during radical nephrectomy. Fresh tumors were minced, suspended in Dulbecco's Modified Eagle's Medium/nutrient mixture F-12 (DMEM/F12; Invitrogen, Thermo Fisher Scientific, Inc., Waltham, MA, USA), and mixed with $300 \mathrm{U} / \mathrm{ml}$ collagenase I (Invitrogen, Thermo Fisher Scientific Inc.) and hyaluronidase (Calbiochem; EMD Millipore, Billerica, MA, USA), followed by overnight incubation at $37^{\circ} \mathrm{C}$ in $5 \% \mathrm{CO}_{2}$. Enzymatically disaggregated suspensions were filtered using a $40 \mu \mathrm{m}$ cell strainer and washed twice with phosphate buffered saline (PBS), and red blood cells were lysed with ammonium chloride lysing buffer. The resulting single tumor cells were cultured in DMEM/F12 supplemented with $10 \%$ fetal bovine serum (FBS; Hyclone; GE Healthcare Life Sciences, Logan, UT, USA) at $37^{\circ} \mathrm{C}$ in a humidified atmosphere containing $5 \% \mathrm{CO}_{2}$.

Radiation. Cells were irradiated at room temperature using a ${ }^{60}$ Co laboratory irradiator (Beijing Normal University, Beijing, China) at a dose rate of $1 \mathrm{~Gy} / \mathrm{min}$. The cultured cells were irradiated with a single dose of 3 Gy. For fractionated radiation, cells were either irradiated for 2-3 consecutive days, or sham-irradiated (controls). Irradiated and sham-irradiated cells were cultured for an additional $48 \mathrm{~h}$ and used in subsequent experiments.

Sphere formation assay. Cells were plated at $1 \times 10^{4} /$ well in ultra-low-attachment 6 -well plates and grown in serum-free DMEM/F12, supplemented with $20 \mathrm{ng} / \mathrm{ml}$ epidermal growth factor, $10 \mathrm{ng} / \mathrm{ml}$ human recombinant basic fibroblast growth factor-basic, and 1\% B27 supplement (all from Invitrogen; Thermo Fisher Scientific, Inc.). The medium was changed every 2 days. Following 10 days in culture, colonies containing $>20$ cells were counted. To evaluate cell self-renewal ability, mammospheres were digested with $0.15 \%$ trypsin to be reseeded at $5 \times 10^{3} /$ well.

Side population analysis. Side population (SP) analysis was performed as described by Goodell et al (16) with slight modifications. Briefly, the cells were suspended at a density of $1 \times 10^{6}$ cells $/ \mathrm{ml}$ in pre-warmed DMEM/F12, supplemented with 2\% FBS (Invitrogen; Thermo Fisher Scientific, Inc.) and $10 \mathrm{mmol} / 1$ 4-(2-hydroxyethyl)-1-piperazineethanesulfonic acid (HEPES). This was followed by incubation with $5 \mathrm{mg} / \mathrm{ml}$ Hoechst 33342 (Invitrogen; Thermo Fisher Scientific, Inc.) with or without $50 \mu \mathrm{M}$ verapamil (Sigma-Aldrich, St. Louis, $\mathrm{MO}$, USA), an ABC transporter inhibitor, in the dark at $37^{\circ} \mathrm{C}$ for 90 min with interval mixing. Following staining, cells were washed twice with ice-cold PBS and resuspended in cold PBS. Flow cytometry analysis was subsequently performed using FACSAria II (Becton Dickinson; BD Biosciences, San Jose, CA, USA). Hoechst 33342 was stimulated using a $355 \mathrm{~nm}$ UV laser and detected using a 450/BP50 filter for blue fluorescence and 660/BP50 filter for red fluorescence.

Reverse transcription-quantitative polymerase chain reaction (RT-qPCR) analysis. Total RNA was obtained from cells using
RNAiso Plus (Takara Biotechnology Co., Ltd. Dalian, China), and reverse transcription was performed according to Takara's protocol. qPCR was performed using a SYBR-Green I Master Mix kit (Takara Biotechnology Co., Ltd.) on the Bio-Rad IQ5 Real-Time-PCR reaction system (Bio-Rad Laboratories, Inc., Hercules, CA, USA). The relative amounts of mRNA were calculated from the comparative threshold cycle values using glyceraldehyde 3-phosphate dehydrogenase as a reference gene (all primers depicted in Table I). PCR was carried out with the following cycling conditions: $95^{\circ} \mathrm{C}$ for $2 \mathrm{~min}$ followed by 38 cycles of amplification (denaturation at $95^{\circ} \mathrm{C}$ for $15 \mathrm{sec}$, annealing at $58^{\circ} \mathrm{C}$ for $20 \mathrm{sec}$ and extension at $72^{\circ} \mathrm{C}$ for $30 \mathrm{sec}$ ).

Tumorigenicity assay and in vivo micro-positron emission tomogtaphy (PET) imaging. The study was approved by the Ethics Committee of Zhengzhou University (Zhengzhou, China). Briefly, $1 \times 10^{5}$ cells suspended in $100 \mu 1$ Matrigel (BD Biosciences) were injected subcutaneously into the left flank region of 4-week-old male NOD/SCID mice obtained from the Institute of Laboratory Animal Science, Peking University Health Science Center (Beijing, China). Tumor growth was monitored for 4 weeks following transplantation using a MOSAIC animal PET scanner (Philips Medical Systems, Inc., Bothell, WA, USA). For microPET imaging, the mice were subjected to fasting for $10 \mathrm{~h}$ prior to injection with fluorodeoxyglucose $\left({ }^{18} \mathrm{~F}-\mathrm{FDG}\right)$, but were allowed free access to water. Mice were anesthetized intraperitoneally with $100 \mathrm{mg} / \mathrm{kg}$ pentobarbital (Sigma-Aldrich), and then injected intravenously with $\sim 3.7 \mathrm{MBq}{ }^{18} \mathrm{~F}$-FDG (Department of Nuclear Medicine, Peking University First Hospital, Beijing, China). To quantify the data, the area density of formed tumors was calculated using Gel-Pro Analyzer software ver. 3.0 (Media Cybernetics, Inc., Rockville, MD, USA).

Clone formation assay. For each experiment, a total of 600-1,000 cells were plated in $25 \mathrm{~cm}^{2}$ flasks in triplicate and cultured in DMEM/F12 (supplemented with 10\% FBS). To evaluate the DNA damage checkpoint response, primary ccRCC cells were cultured for $24 \mathrm{~h}$ before incubation with 100 nM AZD7762 (AstraZeneca R\&D, Boston, MA, USA) for $1 \mathrm{~h}$ prior to irradiation and $24 \mathrm{~h}$ following radiation. The cells were cultured for an additional 9 days and subsequently fixed and stained with $0.5 \%$ crystal violet. Colonies containing $>50$ cells were counted. The clone formation efficiency was calculated as the ratio of the clone number to the seeded cell number.

Cell cycle analysis. Irradiated and sham-irradiated cells were pretreated with or without $100 \mathrm{nM}$ AZD7762 (AstraZeneca R\&D) for $1 \mathrm{~h}$. The cells were harvested and washed with PBS $24 \mathrm{~h}$ following radiation, fixed in $70 \%$ ethanol for $30 \mathrm{~min}$ at $4^{\circ} \mathrm{C}$, and stained with PBS containing $40 \mu \mathrm{g} / \mathrm{ml}$ RNaseA and $10 \mu \mathrm{g} / \mathrm{ml}$ propidium iodine, in the dark for $30 \mathrm{~min}$. Cell cycle distribution was measured using the FACSCalibur ${ }^{\mathrm{TM}}$ flow cytometer (BD Biosciences), and data were analyzed using the BD CellQuest ${ }^{\mathrm{TM}}$ software ver. 3.1 (BD Biosciences).

Statistical analysis. Data are expressed as means \pm SEM $(n=3)$. The differences between SP cells were analyzed using Student's t-test. Statistical analyses were performed using 
Table I. Primer sequences used in RT-qPCR.

\begin{tabular}{|c|c|c|}
\hline Gene & Sense and anti-sense ( $5^{\prime}$ to $\left.3^{\prime}\right)$ & Product size (bp) \\
\hline \multirow[t]{2}{*}{ ATM } & CCAAGTATGTAACCAACAATAGAAGAAG & 81 \\
\hline & TGGATCCAGCTATTTGGTTTGA & \\
\hline \multirow[t]{2}{*}{ ATR } & TGTCTCTACTCTTCACGGCATGTT & 82 \\
\hline & AAGAGGTCCACATGTCCGTGTT & \\
\hline \multirow[t]{2}{*}{ Bmi1 } & AAATGCTGGAGAACTGGAAAG & 124 \\
\hline & CTGTGGATGAGGAGACTGC & \\
\hline \multirow[t]{2}{*}{ Chk1 } & TTGGATAAACAGGGAAGTGAACAC & 108 \\
\hline & GGTGAATATAGTGCTGCTATGTTGACA & \\
\hline \multirow[t]{2}{*}{ Chk2 } & CCCAAGGCTCСТССТСАСА & 81 \\
\hline & AGTGAGAGGACTGGCTGGAGTT & \\
\hline \multirow[t]{2}{*}{ GAPDH } & AATTGAGCCCGCAGCCTCCC & 153 \\
\hline & CCAGGCGCCCAATACGACCA & \\
\hline \multirow[t]{2}{*}{ Nanog } & ATTCAGGACAGCCCTGATTCTTC & 76 \\
\hline & TTTTTGCGACACTCTTCTCTGC & \\
\hline \multirow[t]{2}{*}{ Oct4 } & GTGGAGAGCAACTCCGATG & 86 \\
\hline & TGCTCCAGCTTCTCCTTCTC & \\
\hline \multirow[t]{2}{*}{ Sox 2} & CGAGTGGAAACTTTTGTCGGA & 74 \\
\hline & TGTGCAGCGCTCGCAG & \\
\hline
\end{tabular}

RT-qPCR, reverse transcription-quantitative polymerase chain reaction; ATM, ataxia-telangiectasia-mutated serine/threonine kinase; ATR, ATM and Rad3-related serine/threonine kinase; Chk1, checkpoint kinase 1; Chk2, checkpoint kinase 2; GAPDH, glyceraldehyde 3-phosphate dehydrogenase.

SPSS software, ver. 17 (SPSS, Inc., Chicago, IL, USA). P<0.05 was considered to indicate a statistically significant difference.

\section{Results}

Increased self-renewal capacity and expression of stemness genes following fractionated radiation treatment. The intrinsic or acquired resistance of RCC cells to current therapeutic strategies severely limits their efficacy, and most patients with RCC succumb to the disease following the failure of current treatments. However, the molecular mechanisms contributing to the radioresistance of RCC tumors remain largely unknown. Therefore, the present study investigated whether TICs are enriched after receiving clinical fractions of radiation. Freshly isolated primary ccRCC cells were irradiated as follows: i) A single dose of $3 \mathrm{~Gy}$ on day 3 (R1); ii) 2 daily doses of 3 Gy on day 2 (R2); or iii) 3 daily doses of 3 Gy on day 1 (R3). Corresponding controls (CTR) were sham-irradiated on day 3. Following irradiation, the cells were incubated for an additional $48 \mathrm{~h}$ to simulate a typical weekend treatment gap.

Sphere formation is a well-described characteristic of TICs, reflecting their potential for self-renewal (17). Thus, the capacity for sphere formation by primary ccRCC cells following multiple rounds of fractionated radiation was evaluated in non-adherent and serum-starved medium. Mammospheres containing $>20$ cells were counted following 10 days in culture (Fig. 1A). The rate of sphere formation in cells from the CTR, R1, R2, and R3 groups were $5.59 \pm 0.90,5.42 \pm 1.12,7.86 \pm 1.07$, and $10.98 \pm 2.47 \%$ respectively (Fig. 1B). The R3 group exhibited a $\sim 2$ fold higher frequency of mammosphere formation than that of the CTR group (Fig. 1B). The self-renewal capacity of primary formed mammospheres was analyzed among the four groups by dissociating the mammospheres into single cells, and reculturing them in tumor sphere medium. The rate of sphere formation in secondary mammospheres was $14.84 \pm 1.98 \%$ in the CTR, $15.18 \pm 2.10 \%$ in $\mathrm{R} 1,14.71 \pm 1.82 \%$ in $\mathrm{R} 2$, and $13.76 \pm 1.88 \%$ in R3 (Fig. 1B). The secondary frequencies of spherical colony formation were similar among all the groups, indicating that capacity for self-renewal was retained after irradiation.

TICs display conserved stem and progenitor cell phenotypes $(7,18)$; therefore, the expression of embryonic stem cell (ES)-associated genes was evaluated to confirm the stemness phenotype of cells subjected to fractionated radiation. RT-qPCR results demonstrated that the R2 and R3 groups expressed ES marker genes, such as Bmi1, Nanog, Sox 2 and Oct4, more highly than CTR (Fig. 1C).

Fractionated irradiated cells exhibit high tumorigenicity and contain a larger SP. Tumorigenic capacity of TICs was determined by injecting immunocompromised mice with RCC cells, using a widely accepted assay $(19,20)$. To determine whether irradiated cells exhibit higher tumorigenicity, the cells were injected subcutaneously into the left flank region of NOD/SCID mice. The Tumor growth of mice injected with cells from each group (CTR, R1, R2, and R3) was monitored at 4 weeks post-transplantation (Fig. 2A, indicated by arrow). The total densities of formed tumors were $3.29 \pm 1.16$ in CTR, $4.28 \pm 0.79$ in R1, 6.72 \pm 1.68 in R2, and 11.75 \pm 2.16 in R3 (x10,000; Fig. 2B). The total tumor densities formed in the R3 group were significantly higher than those formed in the CTR group $\left({ }^{* *} \mathrm{P}<0.01\right)$. 


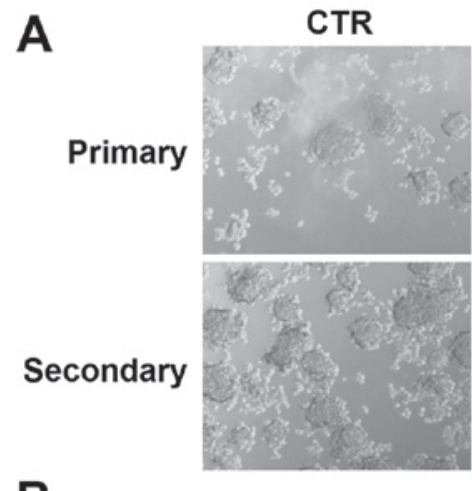

B

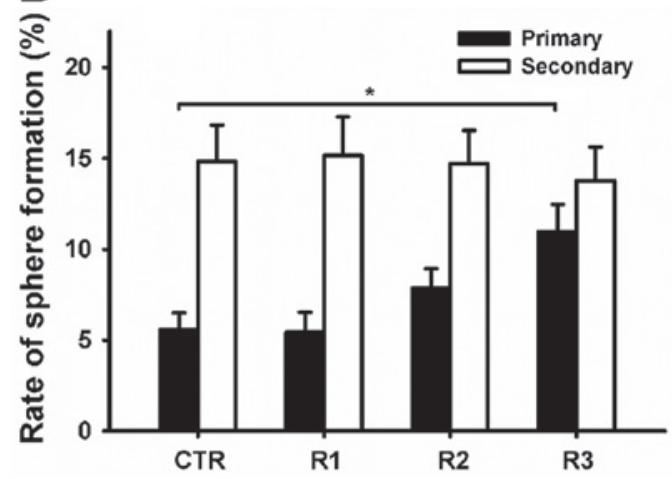

R1
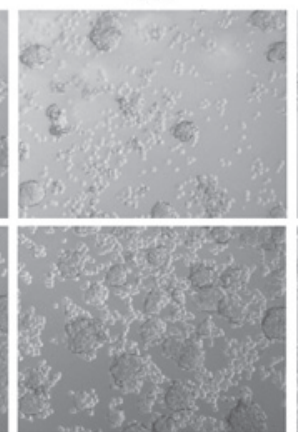

C
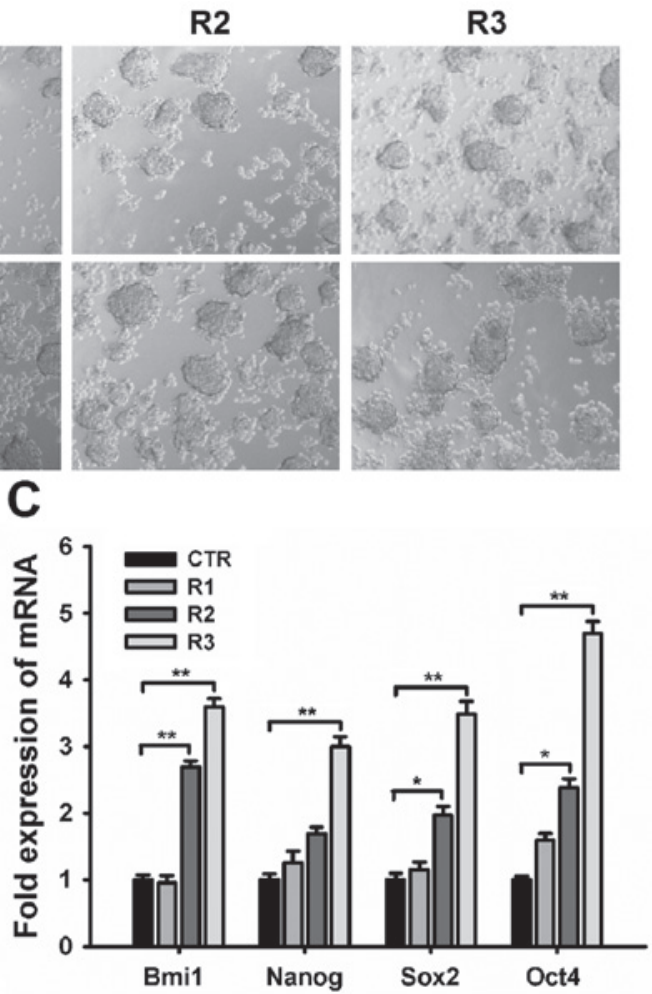

Figure 1. Increased sphere formation capacity and expression of the stemness genes Bmi1, Nanog, Sox 2 and Oct4, following fractionated irradiation. On day 10, primary and secondary spheres (derived from single cells of primary mammospheres) were (A) photographed and counted, to (B) calculate the rate of sphere formation ( $\left.{ }^{*} \mathrm{P}<0.05\right)$. (C) RT-qPCR expression analysis of stemness genes $\left({ }^{*} \mathrm{P}<0.05,{ }^{* *} \mathrm{P}<0.01\right)$. RT-qPCR, reverse transcription-quantitative polymerase chain reaction.

Previous studies have demonstrated that SPs within different cancer cells are less differentiated and have characteristics of stem/progenitor cells $(7,16,21)$. In addition, it has been confirmed that SP cells in RCCs exhibit TIC characteristics $(8,9,22)$. Fig. 2C presents the fraction of SP cells observed within each group. These were $3.84,3.89,4.97$ and $6.82 \%$ in the CTR, R1, R2, and R3 groups, respectively. The frequency of SP cells increased from $3.84 \%$ in the CTR group to $6.82 \%$ in the $\mathrm{R} 3$ group $(\mathrm{P}<0.05$; Fig. $2 \mathrm{C})$, demonstrating enrichment of the SP fraction that occurred following fractionated radiation treatment.

Upregulation of DNA damage checkpoint genes after fractionated radiation. The TIC subpopulation was enriched following fractionated radiation, suggesting that TICs within primary ccRCC mediate resistance to ionizing radiation. DNA damage leads to radiation-induced cell lethality; therefore the DNA damage checkpoint response serves an essential role in cellular radiosensitivity $(23,24)$. To determine the role of the DNA damage checkpoint response in TIC radioresistance, the present study examined the expression of DNA damage checkpoint-associated genes including ataxia-telangiectasia-mutated serine/threonine kinase (ATM), ATM and Rad3-related serine/threonine kinase (ATR), checkpoint kinase 1 (Chk1), and Chk2. The expression levels of ATM, Chk1, and Chk2 were significantly higher in cells subjected to fractionated irradiation than in sham-irradiated cells (Fig. 3A), however, no significant difference in ATR gene expression was observed among the four groups. These data indicate that fractionated irradiated cells may activate checkpoint responses to a greater extent than sham-irradiated cells, suggesting that the radiation resistance of enriched TICs is due to increased checkpoint activation.

A novel checkpoint kinase inhibitor, AZD7762, was used to confirm the above hypothesis. Results from the clonogenic survival assay demonstrated that $100 \mathrm{nM}$ AZD7762 exerted minimal cytotoxicity in the CTR group but yielded radiation enhancement effects that overcome the resistance of irradiated cells, significantly reducing the rate of clone formation in R2 and $\mathrm{R} 3$ cells (Fig. 3B and $\mathrm{C} ; \mathrm{P}<0.05$ ). These data confirm that the preferential checkpoint response in radiation-enriched TICs is associated with cellular resistance to radiation.

Arrest of fractionated radiated cells in G2/M phase. Checkpoint activation induces cell-cycle arrest in order to repair damaged DNA. Therefore, the cell cycle distribution among the four groups was analyzed. Cell cycle analysis revealed induction of $\mathrm{G} 2 / \mathrm{M}$ arrest following irradiation with $3 \times 3 \mathrm{~Gy}$; from $12.94 \pm 0.47$ (CTR) to $32.57 \pm 1.58 \%$ (R3 group; Fig. 4A). This arrest was abolished by AZD7762 administration. AZD7762 specifically abrogated the G2 checkpoint as evidenced by an increased G1 cell population in groups R2 and 3 (Fig. 4B and C). These results indicate that cells exposed to fractionated radiation were arrested in the $\mathrm{G} 2 / \mathrm{M}$ phase, due to the induction of the DNA damage checkpoint response, possibly via Chk1 and Chk2.

\section{Discussion}

In this study, a TIC-like subpopulation was enriched following exposure to fractionated radiation. This subpopulation 
A

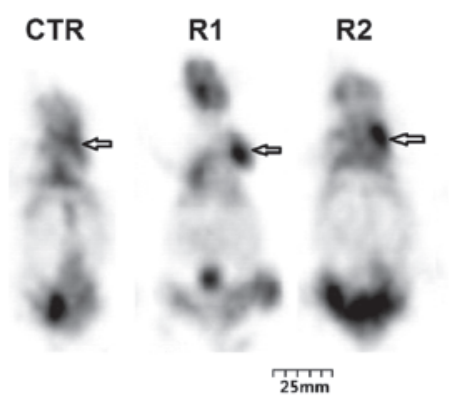

C

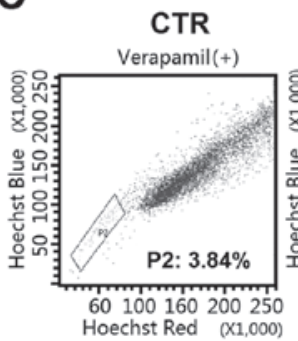

Verapamil(-)

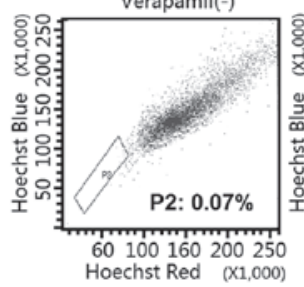

B

R3

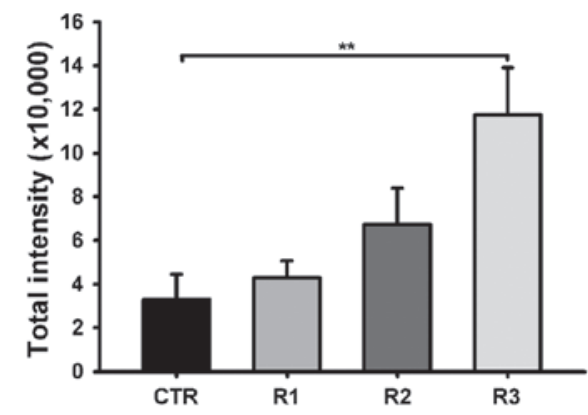

Figure 2. Fractionated irraditated cells display higher tumorigenicity and contain a larger SP fraction. Cells from each group (CTR, R1, R2, and R3) were injected subcutaneously into the left flank region of NOD/SCID mice. (A) Tumor growths (indicated by arrow) were monitored for 4 weeks by microPET imaging. (B) The optical density of formed tumors was calculated using Gel-Pro Analyzer ( $\left.{ }^{* *} \mathrm{P}<0.01\right)$. (C) The fraction of SP cells within fractionated irradiated and sham-irradiated cells. SP, side population.

A

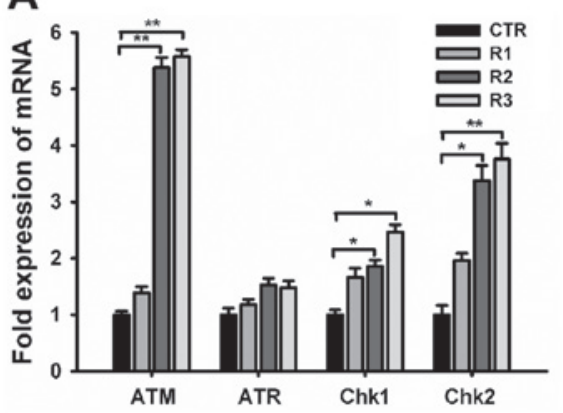

C

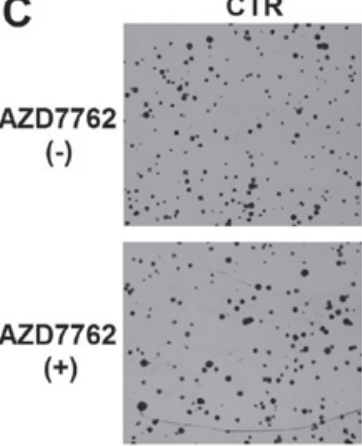

R1

Verapamil(+)

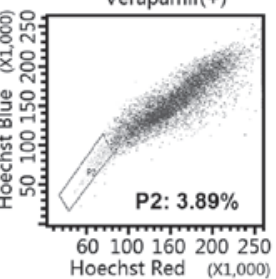

Verapamil( $(-)$

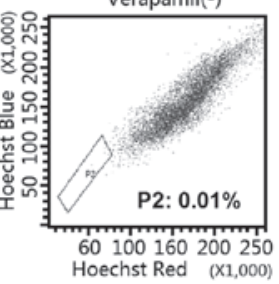

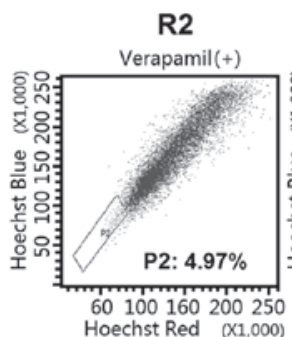
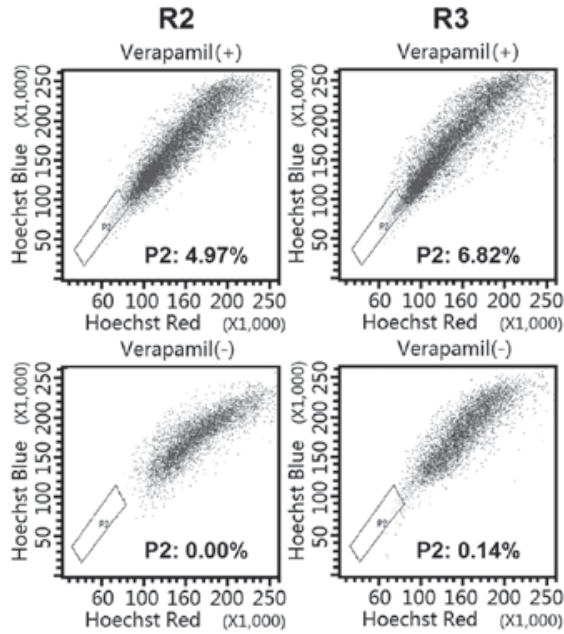

B

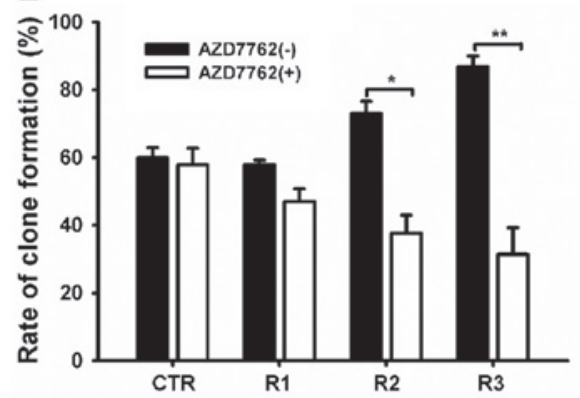

R2
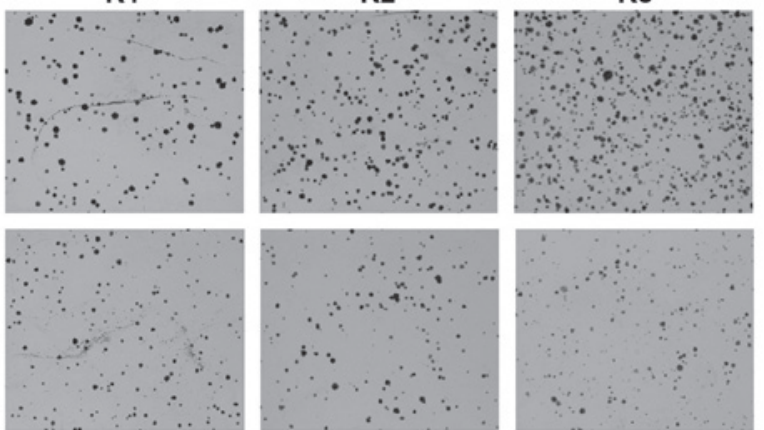

Figure 3. Activation of the DNA damage checkpoint response following fractionated radiation. (A) RT-qPCR analysis of DNA damage checkpoint-associated gene expression $\left({ }^{*} \mathrm{P}<0.05,{ }^{* *} \mathrm{P}<0.01\right)$. Cells were cultured for $24 \mathrm{~h}$ and treated with or without $100 \mathrm{nM}$ AZD7762 for $1 \mathrm{~h}$ prior to irradiation and $24 \mathrm{~h}$ after radiation. Clone formation was (C) photographed (B) and calculated after incubation for another 9 days $\left({ }^{*} \mathrm{P}<0.05\right.$, $\left.{ }^{* *} \mathrm{P}<0.01\right)$. RT-qPCR, reverse transcription-quantitative polymerase chain reaction; ATM, ataxia-telangiectasia-mutated; ATR, ATM and Rad3-related serine/threonine kinase; Chk1, checkpoint kinase 1; Chk2, checkpoint kinase 2; AZD7762, checkpoint kinase inhibitor. 
A

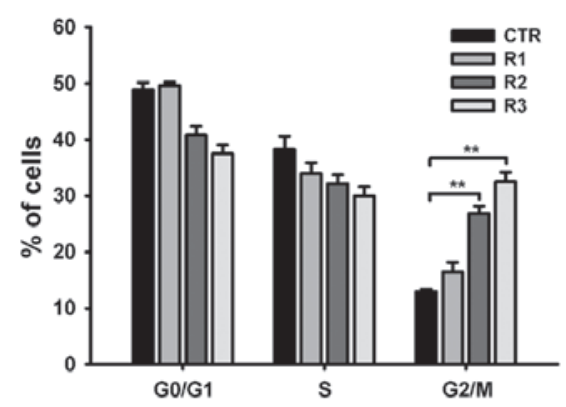

B

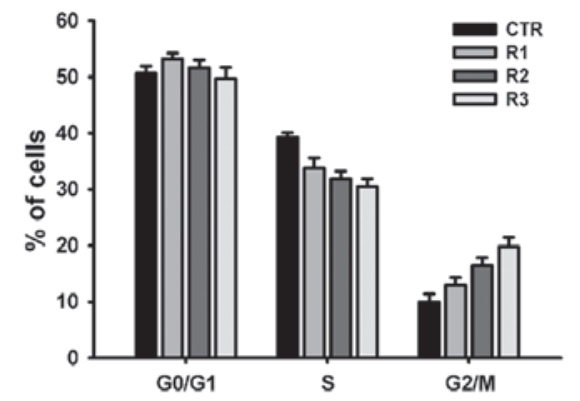

C

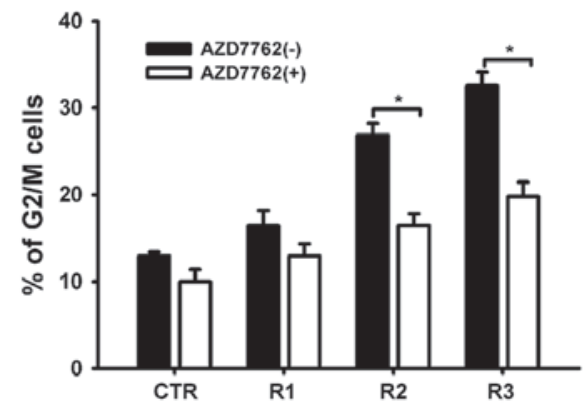

Figure 4. Fractionated radiated cells were arrested in the G2/M phase. Cells were cultured for $24 \mathrm{~h}$ and treated (B) with or (A) without 100 nM AZD7762 for $1 \mathrm{~h}$ prior to irradiation and $24 \mathrm{~h}$ after radiation. The cell cycle distribution of the total population was subsequently analyzed by flow cytometry. (C) Percentage of cells from each group in the $\mathrm{G} 2 / \mathrm{M}$ phase after irradiation following treatment both with or without $100 \mathrm{nM}$ AZD7762 ("P<0.05, $\left.{ }^{* *} \mathrm{P}<0.01\right)$. AZD7762, checkpoint kinase inhibitor.

displayed preferential activation of DNA damage checkpoint-associated genes, resulting in cell cycle arrest to repair damaged DNA.

TICs are known to mediate tumor cell resistance to current therapeutic options, and serve as candidate biological targets for overcoming resistance to conventional therapy. Previous studies have isolated and identified a TIC-like subpopulation of cells from RCC (9-14) using approaches based on the notion that TICs have conserved stem and progenitor cell functions and phenotypes $(7,25)$. However, the associations among the different TIC populations isolated remain unclear. Methods of isolating TICs may not be the same for each type of tumor cell $(7,26)$. For example, the sphere-forming assay is a relatively simple yet robust method for isolating and expanding stem cell populations; however, there is scant definitive information regarding what type of cancer cells are propagated under these conditions (26). Surface marker-based cell sorting is a widely used method, however, its frequency is highly variable even among the same type of cancer cell. Therefore, TICs may exhibit heterogeneity and display several common markers (7).

The current study demonstrated the enrichment of TIC-like cells following their exposure to fractionated radiation. The cells that survived displayed TIC features, including an increased propensity to form mammospheres (Fig. 1), tumorigenicity (Fig. 2), and heightened clonogenic efficiency (Fig. 3), compared with sham-irradiated cells. The surviving cells also expressed higher levels of ES-associated genes, such as Bmi1, Nanog, Sox2, and Oct4 (Fig. 1). Furthermore, the results indicated that the SP was enriched during fractionated irradiation (Fig. 2). Therefore, the results of the current study provides direct evidence that TIC cells are present in radiation resistant ccRCC cells.

The secondary frequency of spherical colonies indicated that fractionated irradiation had no significant effects on the self-renewing capacity of surviving ccRCC cells (Fig. 1), suggesting that fractionated radiation may be a valuable method of enriching TIC subpopulations. This may be useful for future investigations into radiation resistance. The heterogenicity of the TIC population was retained to a large extent in this selection model, compared with the traditional cell sorting isolation method, often based on surface markers.
Accumulating evidence suggests that TIC resistance to ionizing radiation may arise from enhanced DNA repair, quiescence propensity, mechanisms of free-radical scavenging, upregulated cell cycle control and specific interaction with the stromal microenvironment $(15,27)$. The biological efficacy of ionizing radiation is dependent mainly on its ability to stimulate DNA lesions. DNA damage may induce cell cycle arrest to preserve DNA integrity, through the DNA damage checkpoint response $(23,24)$. In response to DNA damage, two critical genes, ATM and ATR, initiate cell cycle arrest via Chk1 and Chk2 (28). ATM activation is generally considered to be a response to DNA lesions induced by irradiation, whereas ATR activation is primarily sensitive to UV damage. The ATM/ATR-Chk signaling pathway triggers G2/M phase arrest through the inhibition of cyclin-dependant protein kinase, allowing damaged DNA to undergo repair $(28,29)$. The ability to repair DNA damage is essential to cellular survival, as DNA lesions may induce apoptosis and senescence $(24,30)$.

The present study demonstrated that the expression of ATM, Chk1, and Chk2 (but not ATR) were all significantly upregulated following fractionated irradiation exposure, and the irradiated cells were arrested in G2/M phase (Figs. 3 and 4). Thus, the survival of TIC-like cells following fractionated radiation may be partly attributed to heightened checkpoint activation, which mediates G2/M arrest. This was confirmed by the fact that AZD7762 (a novel checkpoint kinase inhibitor) abrogated the G2/M phase arrest and induced ccRCC cell sensitivity to irradiation (Figs. 3 and 4).

In conclusion, the present study demonstrated that TIC-like cells were enriched after fractionated radiation. This enriched subpopulation of cells within ccRCC tumors may contribute to ccRCC radioresistance by activating the DNA damage checkpoint response and arresting the cell cycle within the G2/M phase, thus facilitating the repair of damaged DNA. Therefore, the DNA damage checkpoint signal pathway may be a potential therapeutic target for overcoming ccRCC resistance to radiotherapy.

\section{Acknowledgements}

The present study was supported by the State Key Clinical Specialty Construction Project of China (grant no. 2013-544). 


\section{References}

1. Rini BI, Campbell SC and Escudier B: Renal cell carcinoma. Lancet 373: 1119-1132, 2009.

2. Ljungberg B, Hanbury DC, Kuczyk MA, Merseburger AS, Mulders PF, Patard JJ and Sinescu IC; European Association of Urology Guideline Group for renal cell carcinoma: Renal cell carcinoma guideline. Eur Urol 51: 1502-1510, 2007.

3. Siegel R, Ma J, Zou Z and Jemal A: Cancer statistics, 2014. CA Cancer J Clin 64: 9-29, 2014.

4. Flanigan RC, Campbell SC, Clark JI and Picken MM: Metastatic renal cell carcinoma. Curr Treat Options Oncol 4: 385-390, 2003.

5. Albiges L, Choueiri T, Escudier B, Galsky M, George D, Hofmann F, Lam T, Motzer R, Mulders P, Porta C, et al: A systematic review of sequencing and combinations of systemic therapy in metastatic renal cancer. Eur Urol 67: 100-110, 2015.

6. De Meerleer G, Khoo V, Escudier B, Joniau S, Bossi A, Ost P, Briganti A, Fonteyne V, Van Vulpen M, Lumen N, et al: Radiotherapy for renal-cell carcinoma. Lancet Oncol 15: e170-e177, 2014.

7. Gao YJ, Li B, Wu XY, Cui J and Han JK: Thyroid tumor-initiating cells: Increasing evidence and opportunities for anticancer therapy (Review). Oncol Rep 31: 1035-1042, 2014.

8. Bussolati B, Dekel B, Azzarone B and Camussi G: Human renal cancer stem cells. Cancer Lett 338: 141-146, 2013.

9. Huang B, Huang YJ, Yao ZJ, Chen X, Guo SJ, Mao XP, Wang DH, Chen JX and Qiu SP: Cancer stem cell-like side population cells in clear cell renal cell carcinoma cell line 769P. PLoS One 8: e68293, 2013.

10. Ueda K, Ogasawara S, Akiba J, Nakayama M, Todoroki K, Ueda K, Sanada S, Suekane S, Noguchi M, Matsuoka K and Yano H: Aldehyde dehydrogenase 1 identifies cells with cancer stem cell-like properties in a human renal cell carcinoma cell line. PLoS One 8: e75463, 2013.

11. Bussolati B, Bruno S, Grange C, Ferrando U and Camussi G: Identification of a tumor-initiating stem cell population in human renal carcinomas. FASEB J 22: 3696-3705, 2008.

12. Zhong Y, Guan K, Guo S, Zhou C, Wang D, Ma W, Zhang Y, Li C and Zhang S: Spheres derived from the human SK-RC-42 renal cell carcinoma cell line are enriched in cancer stem cells. Cancer Lett 299: 150-160, 2010.

13. Galleggiante V, Rutigliano M, Sallustio F, Ribatti D, Ditonno P, Bettocchi C, Selvaggi FP, Lucarelli G and Battaglia M: CTR2 identifies a population of cancer cells with stem cell-like features in patients with clear cell renal cell carcinoma. J Urol 192: 1831-1841, 2014.

14. Lucarelli G, Galleggiante V, Rutigliano M, Vavallo A, Ditonno P and Battaglia M: Isolation and characterization of cancer stem cells in renal cell carcinoma. Urologia 82: 46-53, 2015.
15. Pajonk F, Vlashi E and McBride WH: Radiation resistance of cancer stem cells: The 4 R's of radiobiology revisited. Stem Cells 28: 639-648, 2010.

16. Goodell MA, Brose K, Paradis G, Conner AS and Mulligan RC: Isolation and functional properties of murine hematopoietic stem cells that are replicating in vivo. J Exp Med 183: 1797-1806, 1996.

17. Pastrana E, Silva-Vargas V and Doetsch F: Eyes wide open: A critical review of sphere-formation as an assay for stem cells. Cell Stem Cell 8: 486-498, 2011.

18. Zhang P, Zhang Y, Mao L, Zhang Z and Chen W: Side population in oral squamous cell carcinoma possesses tumor stem cell phenotypes. Cancer Lett 277: 227-234, 2009.

19. Welte Y, Adjaye J, Lehrach HR and Regenbrecht CR: Cancer stem cells in solid tumors: Elusive or illusive? Cell Commun Signal 8: 6, 2010.

20. Clarke MF, Dick JE, Dirks PB, Eaves CJ, Jamieson CH, Jones DL, Visvader J, Weissman IL and Wahl GM: Cancer stem cells-perspectives on current status and future directions: AACR workshop on cancer stem cells. Cancer Res 66: 9339-9344, 2006.

21. Golebiewska A, Brons NH, Bjerkvig R and Niclou SP: Critical appraisal of the side population assay in stem cell and cancer stem cell research. Cell Stem Cell 8: 136-147, 2011.

22. Nishizawa S, Hirohashi Y, Torigoe T, Takahashi A, Tamura Y, Mori T, Kanaseki T, Kamiguchi K, Asanuma H, Morita R, et al: HSP DNAJB8 controls tumor-initiating ability in renal cancer stem-like cells. Cancer Res 72: 2844-2854, 2012.

23. Sancar A, Lindsey-Boltz LA, Unsal-Kaçmaz K and Linn S: Molecular mechanisms of mammalian DNA repair and the DNA damage checkpoints. Annu Rev Biochem 73: 39-85, 2004.

24. Carr AM: DNA structure dependent checkpoints as regulators of DNA repair. DNA Repair (Amst) 1: 983-994, 2002.

25. Dalerba P, Cho RW and Clarke MF: Cancer stem cells: Models and concepts. Annu Rev Med 58: 267-284, 2007.

26. Visvader JE and Lindeman GJ: Cancer stem cells in solid tumours: Accumulating evidence and unresolved questions. Nat Rev Cancer 8: 755-768, 2008.

27. Moncharmont C, Levy A, Gilormini M, Bertrand G, Chargari C, Alphonse G, Ardail D, Rodriguez-Lafrasse C and Magné N: Targeting a cornerstone of radiation resistance: Cancer stem cell. Cancer Lett 322: 139-147, 2012.

28. Smith J, Tho LM, Xu N and Gillespie DA: The ATM-Chk2 and ATR-Chk1 pathways in DNA damage signaling and cancer. Adv Cancer Res 108: 73-112, 2010.

29. Enomoto M, Goto H, Tomono Y, Kasahara K, Tsujimura K, Kiyono T and Inagaki M: Novel positive feedback loop between Cdk1 and Chk1 in the nucleus during G2/M transition. J Biol Chem 284: 34223-34230, 2009.

30. Zhou BB and Elledge SJ: The DNA damage response: Putting checkpoints in perspective. Nature 408: 433-439, 2000. 